\title{
Inspiratory Muscle Performance of Former Smokers and Nonsmokers Using the Test of Incremental Respiratory Endurance
}

\author{
Magno F Formiga PT, Michael A Campos MD, and Lawrence P Cahalin PhD PT
}

\begin{abstract}
BACKGROUND: Smoking has potential deleterious effects on respiratory muscle function. Smokers may present with reduced inspiratory muscle strength and endurance. We compared inspiratory muscle performance of nonsmokers with that of former smokers without overt respiratory problems via the Test of Incremental Respiratory Endurance. METHODS: This study was performed on 42 healthy subjects between the ages of 30 and $79 \mathrm{y}$ (mean \pm SD of $56.5 \pm 14.4 \mathrm{y}$ ). Fourteen male and 7 female former smokers were matched to nonsmokers based on sex, age, height, and weight. Subjects completed a questionnaire about their health and current smoking status. Testing included the best of 3 or more consistent trials. The Test of Incremental Respiratory Endurance measurements included maximal inspiratory pressure measured from residual volume as well as sustained maximal inspiratory pressure and inspiratory duration measured from residual volume to total lung capacity during a maximal sustained inhalation. RESULTS: No significant difference in inspiratory performance of the entire group of former smokers compared with nonsmokers was found. However, separate sex analyses found a significant difference in sustained maximal inspiratory pressure between male former smokers and nonsmokers $(518.7 \pm \mathbf{2 0 5 . 0}$ pressure time units vs 676.5 \pm 255.2 pressure time units, $P=.041)$. CONCLUSIONS: We found similar maximal inspiratory pressure between former smokers and nonsmokers via the Test of Incremental Respiratory Endurance, but the significant difference in sustained maximal inspiratory pressure between male former smokers and nonsmokers suggests that the sustained maximal inspiratory pressure may have greater discriminatory ability in assessing the effects of smoking on inspiratory muscle performance. Further investigation of the effects of smoking on inspiratory performance via the Test of Incremental Respiratory Endurance is warranted. Key words: cigarette smoking; smoking cessation; respiratory muscle; maximal respiratory pressures; maximal inspiratory pressure; respiratory muscle training. [Respir Care 2018;63(1):86-91. (C) 2018 Daedalus Enterprises]
\end{abstract}

\section{Introduction}

Cigarette smoking is recognized as the main causative factor for the development of COPD in developed countries. COPD is characterized by a progressive deterioration in exercise capacity in association with weakness and de-

\footnotetext{
Mr Formiga and Dr Cahalin are affiliated with the Department of Physical Therapy, University of Miami Miller School of Medicine, Coral Gables, Florida. Mr Formiga is also affiliated with the CAPES Foundation, Ministry of Education of Brazil, Brasilia, Brazil. Dr Campos is affiliated with the Division of Pulmonary, Allergy, Critical Care, and Sleep Medicine, University of Miami Miller School of Medicine, Miami, Florida.
}

The authors have disclosed no conflicts of interest. conditioning of the respiratory muscles. Inspiratory muscle performance is particularly impaired in COPD with reductions in both strength and endurance. ${ }^{1,2}$ Whereas patients with COPD suffer from inspiratory muscle dysfunction, such worsening in inspiratory performance may be noticeable in former smokers without a diagnosis of obstructive lung disease. Several studies suggest that smok-

\footnotetext{
Correspondence: Lawrence P Cahalin PhD PT, University of Miami Miller School of Medicine, Department of Physical Therapy, 5915 Ponce de Leon Boulevard, 5th Floor, Coral Gables, FL 33146-2435. E-mail: 1.cahalin@miami.edu.
}

DOI: $10.4187 /$ respcare.05716 
ing per se, regardless of the presence of COPD, has the potential to negatively affect skeletal muscle function. ${ }^{3-5}$

Several previous studies have examined the effects of smoking on respiratory muscle function and have found different results. Some investigators ${ }^{6-10}$ found no significant difference in inspiratory muscle strength between active smokers and nonsmokers, whereas one study of elderly subjects found that current smokers had significantly lower maximal inspiratory pressure $\left(\mathrm{P}_{\text {Imax }}\right)$ values than nonsmokers. ${ }^{11}$ Another large study of $>13,000$ subjects also found that current smokers had significantly lower $\mathrm{P}_{\text {Imax }}$ values than nonsmokers. ${ }^{12}$ Finally, one study of chronic heavy smokers found a slight increase in $\mathrm{P}_{\operatorname{Imax}} \cdot{ }^{13}$ In view of the above mixed observations, further investigation of the effects of smoking on inspiratory muscle performance is needed. Even more unclear is whether there is a residual effect of smoking on inspiratory muscle strength and endurance in former smokers.

The Test of Incremental Respiratory Endurance provides a novel assessment of inspiratory performance by measuring $\mathrm{P}_{\text {Imax }}$, sustained $\mathrm{P}_{\text {Imax }}$, and inspiratory duration during a maximal sustained inhalation. The $\mathrm{P}_{\text {Imax }}$ is related to inspiratory muscle strength and is defined as the highest pressure achieved during inspiration measured from residual volume $(\mathrm{RV})$, whereas sustained $\mathrm{P}_{\text {Imax }}$ is measured from RV to total lung capacity and is described as singlebreath inspiratory work/endurance capacity. ${ }^{14}$ The effect of smoking on inspiratory muscle performance assessed through the Test of Incremental Respiratory Endurance has not been previously examined. The purpose of the following study was to compare inspiratory performance of nonsmokers with that of former smokers without overt respiratory problems via the Test of Incremental Respiratory Endurance. We hypothesized that former smoking would negatively affect inspiratory muscle strength and endurance.

\section{Methods}

The study was performed with a convenience sample of 42 healthy subjects between the ages of 30 and $79 \mathrm{y}$ (mean \pm SD of $56.5 \pm 14.4 \mathrm{y}$ ) who were participants in a larger study $(n=120)$ that developed normative Test of Incremental Respiratory Endurance values in late 2015.15 Fourteen male and 7 female former smokers were matched to nonsmokers based on their sex, age, height, and weight. Before being tested, all subjects signed a written informed consent and completed a questionnaire about their overall health, medical history, and smoking status. Subjects were classified as former smokers if they responded both verbally and in writing via questionnaire that they were not currently smoking but had smoked in the past and were not previously diagnosed with a respiratory disorder. Subjects were classified as nonsmokers if they responded both ver-

\section{QUICK LOOK}

\section{Current knowledge}

Cigarette smoking is the main causative factor for the development of COPD. Whereas inspiratory muscle strength and endurance are particularly impaired in this condition, such worsening in inspiratory muscle performance is also noted in cigarette smokers without a diagnosis of lung disease. Smoking per se has the potential to negatively affect skeletal muscle function.

\section{What this paper contributes to our knowledge}

The sustained maximal inspiratory pressure, a measure of single-breath inspiratory work/endurance capacity, appears to have greater value in assessing the effects of smoking on inspiratory muscle function when compared with the most commonly studied measure of maximal inspiratory pressure.

bally and in writing via questionnaire that they never smoked and were not previously diagnosed with a respiratory disorder. The University of Miami institutional review board approved all procedures.

\section{Test of Incremental Respiratory Endurance}

The Test of Incremental Respiratory Endurance was implemented via the RT2 device (DeVilbiss Healthcare United Kingdom Ltd, Tipton, United Kingdom), which utilizes an infrared link to a computer and provides the user with a graphic representation of their inspiratory effort throughout all of inspiration and real-time biofeedback. ${ }^{14}$ The Test of Incremental Respiratory Endurance RT2 device incorporates a standard 2-mm leak to avoid glottal closure during maximal inspiration. All measurements were performed with the subjects seated in a chair and wearing nose clips using American Thoracic Society standards for respiratory muscle testing ${ }^{16}$ as shown in Figure 1.

Subjects were instructed to inspire deeply, generating as much pressure as possible within 1-2 s of inspiration, and to continue to inspire maximally for as long as possible. The $\mathrm{P}_{\text {Imax }}$ was measured from $\mathrm{RV}$, and the sustained $\mathrm{P}_{\text {Imax }}$ was measured from RV to total lung capacity. Three to five consecutive trials were performed with rest intervals of $60 \mathrm{~s}$ between efforts. Visual feedback and strong encouragement were given throughout testing. For each successful inspiratory effort, $\mathrm{P}_{\text {Imax }}$ was recorded in $\mathrm{cm} \mathrm{H}_{2} \mathrm{O}$, and sustained $\mathrm{P}_{\text {Imax }}$ was documented in pressure time units, representing the area under the curve generated from the start to the end of inspiration. The inspiratory duration was recorded in seconds and characterized the total duration of 


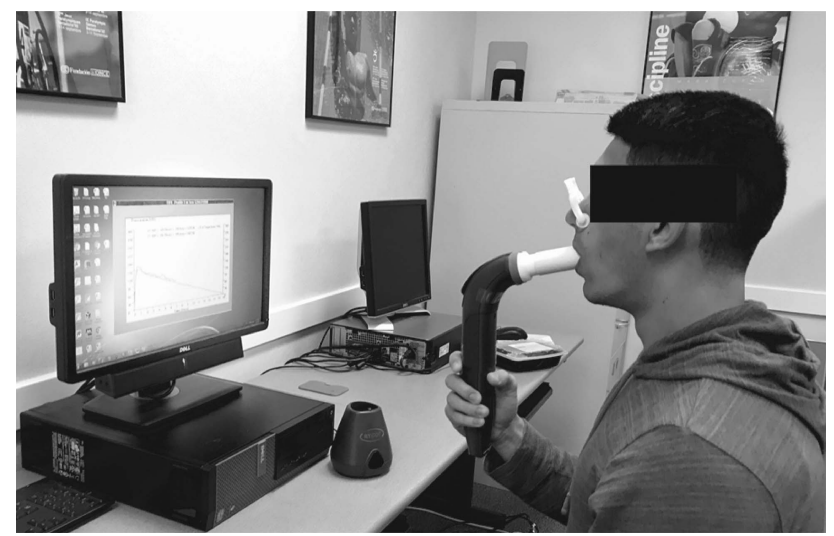

Fig. 1. Test of Incremental Respiratory Endurance procedure. Subjects received standardized instructions and encouragement to facilitate maximal performance following American Thoracic Society/European Respiratory Society guidelines.

inspiration during each maximal inspiratory effort from $\mathrm{RV}$ to total lung capacity through the 2-mm leak of the Test of Incremental Respiratory Endurance RT2 mouthpiece, thus providing another measure of inspiratory muscle endurance. Figure 2 presents an example of a Test of Incremental Respiratory Endurance graph obtained via the RT2 device.

\section{Statistical Analyses}

Statistical analyses were performed with SPSS Statistics 24 (IBM Corp, Armonk, New York) and included descriptive statistics, a one-tailed independent-samples $t$ test to compare former smokers and nonsmokers, and a one-tailed Mann-Whitney $U$ test to compare former smokers and nonsmokers in separate decades. We also performed Pearson correlation analyses to investigate the relationship between years since smoking cessation and inspiratory muscle performance. The level of significance was set at $P<.05$. A post hoc power analysis was performed using $\mathrm{G}^{*}$ Power 3.1.9.2 (Universität Kiel, Kiel, Germany).

\section{Results}

The mean height, weight, $\mathrm{P}_{\text {Imax }}$, sustained $\mathrm{P}_{\text {Imax }}$, and inspiratory duration of subjects were $170.6 \pm 8.1 \mathrm{~cm}$, $78.6 \pm 14.6 \mathrm{~kg}, 97.5 \pm 22.9 \mathrm{~cm} \mathrm{H}_{2} \mathrm{O}, 554.1 \pm 231.4$ pressure time units, and $11.7 \pm 4.2 \mathrm{~s}$, respectively. The mean \pm SD time since smoking cessation in the group of former smokers was $23.2 \pm 15.3 \mathrm{y}$. No significant correlations were found between years since smoking cessation and the Test of Incremental Respiratory Endurance measures of inspiratory muscle performance. Table 1 presents the descriptive statistics of the former smokers and nonsmokers by sex.

Independent of smoking history, the mean $\mathrm{P}_{\text {Imax }}$, sustained $\mathrm{P}_{\text {Imax }}$, and inspiratory duration of men were significantly greater than those of women (104.9 \pm 22.6 vs $82.5 \pm 15 \mathrm{~cm} \mathrm{H}_{2} \mathrm{O}, 597.6 \pm 240.9$ vs $466.8 \pm 189.7$ pressure time units, and $12.6 \pm 4.2$ vs $9.7 \pm 3.3 \mathrm{~s}$, respectively; $P<.05$ for all).

No significant difference in the mean $\mathrm{P}_{\text {Imax }}$, sustained $\mathrm{P}_{\text {Imax }}$, and inspiratory duration of the entire group of former smokers compared with nonsmokers was found $\left(94 \pm 24.3\right.$ vs $100.9 \pm 21.4 \mathrm{~cm} \mathrm{H}_{2} \mathrm{O}, 513.9 \pm 208.7 \mathrm{vs}$ $594.1 \pm 250.7$ pressure time units, and $11.1 \pm 4.4 \mathrm{vs}$ $12.3 \pm 3.8 \mathrm{~s}$, respectively). Separate sex analyses found a significant difference in sustained $\mathrm{P}_{\text {Imax }}$ between male former smokers and nonsmokers $(518.7 \pm 205.0$ vs $676.5 \pm 255.2$ pressure time units, $P=.041)$. A post hoc power analysis was conducted and revealed that the observed power to detect the computed effect size of .68 $(n=28)$ was .54 . Table 2 summarizes descriptive statistics of study variables across different age groups and smoking history. There were no significant differences in the sustained $\mathrm{P}_{\text {Imax }}$ values of former smokers versus nonsmokers; however, there was a trend $(P=.063)$ for lower values among smokers in the decades 40-49 and 70-79 y.

\section{Discussion}

To the best of our knowledge, this is the first study to compare inspiratory muscle performance measures of former smokers with age- and sex-matched nonsmokers via the Test of Incremental Respiratory Endurance. Previous studies have found disparate effects of smoking on inspiratory muscle strength and endurance measures ${ }^{6-13,17}$ and stressed the need of further evaluation of the effect of smoking on inspiratory muscle performance.

Sustained $\mathrm{P}_{\text {Imax }}$ is represented as the area under the curve in the pressure-time graph generated during the Test of Incremental Respiratory Endurance maneuver (Fig. 2) and represents inspiratory work, power, and endurance. The sustained $\mathrm{P}_{\text {Imax }}$ and its association with smoking have not been previously examined. Whereas we found no significant overall differences in mean sustained $\mathrm{P}_{\text {Imax }}$ values of former smokers compared with those of nonsmokers in the entire sample, we observed that male former smokers had significantly lower sustained $\mathrm{P}_{\text {Imax }}$ values compared with nonsmokers. Furthermore, the nearly significant differences in sustained $\mathrm{P}_{\text {Imax }}$ that we observed between groups in different decades suggest that sustained $\mathrm{P}_{\text {Imax }}$ may be an important measurement to examine the effects of smoking over the long-term and that sustained $\mathrm{P}_{\text {Imax }}$ differences between former smokers and nonsmokers appear to be greater with aging. Although this is particularly important, 


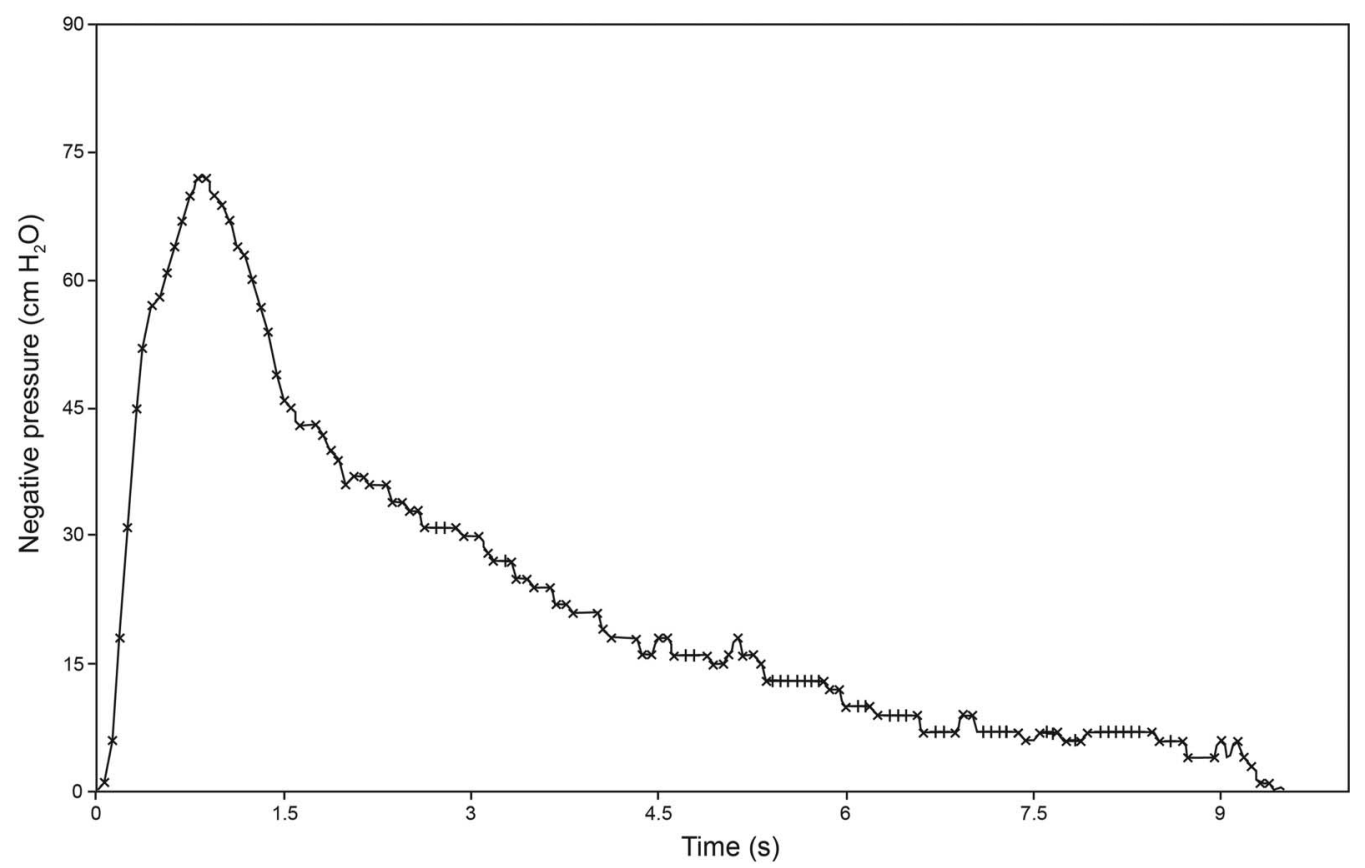

Fig. 2. Test of Incremental Respiratory Endurance template via the RT2 device. Maximal inspiratory pressure $=72 \mathrm{~cm} \mathrm{H}_{2} \mathrm{O}$, sustained maximal inspiratory pressure $=210.6 \mathrm{~cm} \mathrm{H}_{2} \mathrm{O}$, inspiratory duration $=9.5 \mathrm{~s}$.

Table 1. Descriptive Statistics of the Entire Group of Smokers and Nonsmokers by Sex

\begin{tabular}{|c|c|c|c|c|}
\hline \multirow{2}{*}{ Variables } & \multicolumn{2}{|c|}{ Males $(n=28)$} & \multicolumn{2}{|c|}{ Females $(n=14)$} \\
\hline & Former Smokers $(n=14)$ & Nonsmokers $(n=14)$ & Former Smokers $(n=7)$ & Nonsmokers $(n=7)$ \\
\hline Height, cm & $172.2 \pm 6.0$ & $176.5 \pm 5.3$ & $160.7 \pm 6.4$ & $165.8 \pm 6.4$ \\
\hline Weight, $\mathrm{kg}$ & $82.7 \pm 11.1$ & $82.3 \pm 13.8$ & $67.5 \pm 11.8$ & $74.3 \pm 19.7$ \\
\hline $\mathrm{P}_{\text {Imax }}, \mathrm{cm} \mathrm{H}_{2} \mathrm{O}$ & $99.6 \pm 26.3$ & $110.2 \pm 17.8$ & $82.7 \pm 15.8$ & $82.4 \pm 15.4$ \\
\hline Sustained $\mathrm{P}_{\text {Imax }}$, PTU & $518.7 \pm 205.0^{*}$ & $676.5 \pm 255.2$ & $504.4 \pm 232.1$ & $429.3 \pm 144.2$ \\
\hline ID, s & $11.8 \pm 4.7$ & $13.5 \pm 3.7$ & $9.6 \pm 3.8$ & $10.0 \pm 3.3$ \\
\hline \multicolumn{5}{|c|}{$\begin{array}{l}\text { Results are mean } \pm \mathrm{SD} \text {. } \\
* P=.041 \text { comparing male former smokers and nonsmokers. } \\
\mathrm{P}_{\text {Imax }}=\text { maximal inspiratory pressure } \\
\mathrm{PTU}=\text { pressure time units } \\
\text { ID = inspiratory duration }\end{array}$} \\
\hline
\end{tabular}

these results must be cautiously interpreted, given the small sample size of subjects in the decade analyses and the likelihood of a type- 2 error. The above differences between former smokers and nonsmokers within decades in this cross-sectional analysis highlight the need for a longitudinal investigation of inspiratory performance of smokers, former smokers, and nonsmokers via the Test of Incremental Respiratory Endurance.

Our analyses suggest that a history of smoking did not significantly affect $\mathrm{P}_{\text {Imax }}$, a more traditional marker of inspiratory muscle strength, in agreement with findings from a large cross-sectional study of almost 700 subjects by Harik-Khan and co-workers comprising individuals ranging in age between 20 and 90 y. ${ }^{17}$ Several other investi- gators have also found no significant difference in inspiratory muscle strength between smokers and nonsmokers. ${ }^{6-10}$ However, Enright et $\mathrm{a}^{11}$ found that current elderly smokers had significantly lower $\mathrm{P}_{\operatorname{Imax}}$ values, whereas former smoking and pack-years of smoking had no independent association with inspiratory strength. $\mathrm{P}_{\text {Imax }}$ was also found to be negatively associated with cigarette smoking in a very large study of $>13,000$ subjects. ${ }^{12}$ Contrastingly, Chen ${ }^{13}$ found a slight increase in $\mathrm{P}_{\operatorname{Imax}}$ in chronic heavy smokers. Although most of the literature is consistent with our findings and indicates that current or former smoking has no significant effect on $\mathrm{P}_{\text {Imax }}$, it appears that further investigation is warranted, especially as it relates to the effects of smoking on other inspiratory performance mea- 


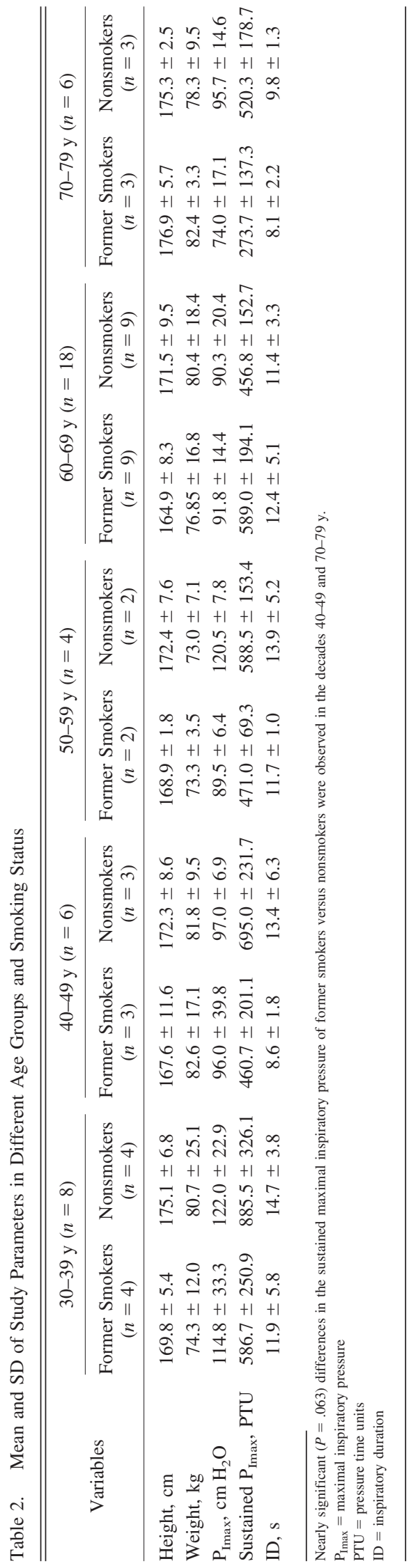

sures, such as the sustained $\mathrm{P}_{\operatorname{Imax}}$ obtained via the Test of Incremental Respiratory Endurance.

The reduction of inspiratory work, power, and endurance via the sustained $\mathrm{P}_{\mathrm{Imax}}$ that we observed in male former smokers and nearly significant differences in several age groups of former smokers versus nonsmokers are consistent with the results obtained by Chen, ${ }^{13}$ who found that long-term smokers presented with a significant decrease in inspiratory work and endurance via the sustainable inspiratory pressure. Chen measured the sustainable inspiratory pressure through a modified threshold loading technique first described by Nickerson and Keens ${ }^{18}$ to identify the highest pressure an individual could achieve during incremental threshold loading. In view of these results, a longitudinal study of long-term smokers via the Test of Incremental Respiratory Endurance focusing on the sustained $\mathrm{P}_{\text {Imax }}$ is particularly warranted.

The inspiratory duration may be another measurement to help identify the effects of smoking and, based on our results shown in Table 2, is worthy of further investigation. Although not statistically different, former smokers were found to have a shorter inspiratory duration compared with nonsmokers in all decades except for 60-69y. There is no previous literature examining the effect of smoking on sustained $\mathrm{P}_{\mathrm{Imax}}$ and inspiratory duration as measures of inspiratory endurance, but our findings suggest that sustained $\mathrm{P}_{\text {Imax }}$ may have greater value in assessing the inspiratory performance of smokers without apparent respiratory disease. Improving an understanding of the effects of smoking on inspiratory performance may educate smokers about yet another adverse effect of smoking and better monitor the effects of chronic smoking in those unable to quit. Further investigation of inspiratory performance in a larger sample of smokers and nonsmokers via the Test of Incremental Respiratory Endurance appears justified, given the potential of the Test of Incremental Respiratory Endurance results for educational and therapeutic purposes as well as monitoring the effects of chronic smoking in subjects unable or unwilling to quit smoking. There appears to be potential for the sustained $\mathrm{P}_{\text {Imax }}$ to capture the deterioration of inspiratory performance in smokers, which may be useful to assist in smoking cessation efforts. Further investigation of the sustained $\mathrm{P}_{\text {Imax }}$ as a smoking cessation tool appears plausible.

This study has a few limitations. First, the relatively small sample size may have contributed to a type-2 error, highlighting that significant differences may in fact be present but not observed because of the small sample size, which is supported by our post hoc power analysis. Whereas we found a significant difference in sustained $\mathrm{P}_{\text {Imax }}$ between male former smokers and male nonsmokers via the Test of Incremental Respiratory Endurance, a more precise and robust assessment of the effects of smoking on inspiratory performance would be better understood by study- 
ing a larger population of male and female smokers and nonsmokers. Another limitation is that at the time of data collection, no details regarding the number of years subjects smoked and the number of pack-years of cigarette smoking were documented. Finally, much of the previous literature used to support or refute our findings is older due to the lack of current studies but still provides important data to compare and contrast with our study findings.

\section{Conclusions}

This study found similar $\mathrm{P}_{\text {Imax }}$ measures between former smokers and nonsmokers via the Test of Incremental Respiratory Endurance, but male former smokers had significantly lower sustained $\mathrm{P}_{\text {Imax }}$ values compared with male nonsmokers. The sustained $\mathrm{P}_{\mathrm{Imax}}$ and inspiratory duration of smokers versus nonsmokers have never been compared, but our findings suggest that these measures may provide a greater degree of discriminatory ability in identifying the effects of smoking on the inspiratory musculature. Further investigation in a larger sample of healthy male and female smokers and nonsmokers via the Test of Incremental Respiratory Endurance in a longitudinal manner is likely to provide a better understanding of the effects of smoking on an individual's inspiratory muscle performance, which may provide several educational, therapeutic, and serial monitoring benefits.

\section{REFERENCES}

1. American Thoracic Society/European Respiratory Society. Skeletal muscle dysfunction in chronic obstructive pulmonary disease: a statement of the American Thoracic Society and European Respiratory Society. Am J Respir Crit Care Med 1999;159(4 Pt 2):S1-S40.

2. Ramirez-Sarmiento A, Orozco-Levi M, Guell R, Barreiro E, Hernandez $\mathrm{N}$, Mota $\mathrm{S}$, et al. Inspiratory muscle training in patients with chronic obstructive pulmonary disease: structural adaptation and physiologic outcomes. Am J Respir Crit Care Med 2002;166(11):14911497.

3. Degens H, Gayan-Ramirez G, van Hees HW. Smoking-induced skeletal muscle dysfunction: from evidence to mechanisms. Am J Respir Crit Care Med 2015;191(6):620-625.
4. Montes de Oca M, Loeb E, Torres SH, De Sanctis J, Hernández N, Tálamo C. Peripheral muscle alterations in non-COPD smokers. Chest 2008;133(1):13-18.

5. Petersen AM, Magkos F, Atherton P, Selby A, Smith K, Rennie MJ, et al. Smoking impairs muscle protein synthesis and increases the expression of myostatin and MAFbx in muscle. Am J Physiol Endocrinol Metab 2007;293(3):E843-E848.

6. Bruschi C, Cerveri I, Zoia MC, Fanfulla F, Fiorentini M, Casali L, et al. Reference values of maximal respiratory mouth pressures: a population-based study. Am Rev Respir Dis 1992;146(3):790-793.

7. Hasan S, Raakkah N, Attaur-rasool S. Effect of smoking on respiratory pressures and lung volumes in young adults. Biomedica 2013; 29:96-100.

8. Vincken W, Ghezzo H, Cosio MG. Maximal static respiratory pressures in adults: normal values and their relationship to determinants of respiratory function. Bull Eur Physiopathol Respir 1987;23(5): 435-439.

9. Tantisuwat A, Thaveeratitham P. Effects of smoking on chest expansion, lung function, and respiratory muscle strength of youths. J Phys Ther Sci 2014;26(2):167-170.

10. Hautmann H, Hefele S, Schotten K, Huber RM. Maximal inspiratory mouth pressures (PIMAX) in healthy subjects-what is the lower limit of normal? Respir Med 2000;94(7):689-693.

11. Enright PL, Kronmal RA, Manolio TA, Schenker MB, Hyatt RE. Respiratory muscle strength in the elderly: correlates and reference values: Cardiovascular Health Study Research Group. Am J Respir Crit Care Med 1994;149(2 Pt 1):430-438.

12. Carpenter MA, Tockman MS, Hutchinson RG, Davis CE, Heiss G. Demographic and anthropometric correlates of maximum inspiratory pressure: the Atherosclerosis Risk in Communities Study. Am J Respir Crit Care Med 1999;159(2):415-422.

13. Chen HI. Effects of chronic smoking on respiratory muscle function. Chin J Physiol 1988;31(1):53-62.

14. Cahalin LP, Arena R. Novel methods of inspiratory muscle training via the Test of Incremental Respiratory Endurance (TIRE). Exerc Sport Sci Rev 2015;43(2):84-92.

15. Cahalin LP, Garcia C, Denis TS, Colas-Salgado S, Eisenhardt B, Formiga MF, et al. Normative values for the Test of Incremental Respiratory Endurance (TIRE). Am J Respir Crit Care Med 2016; 193:A6363.

16. American Thoracic Society/European Respiratory Society. Statement on respiratory muscle testing. Am J Respir Crit Care Med 2002; 166(4):518-624.

17. Harik-Khan RI, Wise RA, Fozard JL. Determinants of maximal inspiratory pressure: the Baltimore Longitudinal Study of Aging. Am J Respir Crit Care Med 1998;158(5 Pt 1):1459-1464.

18. Nickerson BG, Keens TG. Measuring ventilatory muscle endurance in humans as sustainable inspiratory pressure. J Appl Physiol 1982; 52(3):768-772. 